\section{Discussion of "Solution Kinetics of a Cast and Wrought High Strength Aluminum Alloy" and "Influence of Ingot Structure and Processing on Mechanical Properties and Fracture of a High Strength Wrought Aluminum Alloy"*}

\section{P. R. SPERRY}

This discussion pertains to the identification, by the authors, of a soluble phase in aluminum alloy 7075 as $\mathrm{CuAl}_{2}$. Although it in no way affects the results and conclusions drawn by the authors from this work, an error in this identification could be a source of confusion to metallurgists and metallographers who are working with this and similar alloys. The writer has conducted extensive detailed studies of the constitution of the $\mathrm{Al}-\mathrm{Cu}-\mathrm{Mg}-\mathrm{Zn}$ alloy system, with and without common impurities and minor additions, and has established with certitude that the phase in question is actually the ternary phase shown as S-AlCuMg or $\mathrm{Al}_{2} \mathrm{CuMg}$, rather than $\mathrm{CuAl}_{2}$.

The authors had apparently based their identification on variations in copper and magnesium content by microprobe traces across regions containing the phase in question. For some unexplained reason, these traces failed to reveal a high enough concentration of magnesium to be able to conclude that this could be a magnesium-rich phase. By virtue of the high copper concentration, the authors were led to believe that the phase must therefore be $\mathrm{CuAl}_{2}$. If this were so, however, the isothermal sections for the $\mathrm{Al}-\mathrm{Cu}-\mathrm{Mg}-\mathrm{Zn}$ system at $460^{\circ} \mathrm{C}$, developed by Strawbridge et al. ${ }^{20}$ would have to be seriously in error, or else the nonequilibrium conditions in proceeding toward equilibration would be totally inexplicable.

There are enough similarities of $\mathrm{CuAl}_{2}$ to $\mathrm{Al}_{2} \mathrm{CuMg}$ that they can be readily confused in metallographic work. Both can have a light pinkish tinge when aspolished and both show strong birefringence in polarized light examination. However, $\mathrm{Al}_{2} \mathrm{CuMg}$ is more chemically active and can easily be roughened and tarnished by prolonged contact with water during polishing or by etching with acidic solutions. Keller's etch, even when diluted as much as $1: 4$ with water, will darken or roughen this phase to varying degrees, whereas $\mathrm{CuAl}_{2}$ remains light and smooth. Figs. 5(b) and $5(c)$ in the authors' first paper show an appearance which is quite characteristic of $\mathrm{Al}_{2} \mathrm{CuMg}$. This, in itself, is not irrefutable proof of identification, but it suggests that some referee method other than microprobe analysis is required.

The solidification of the basic 7075 alloy composi-

*S. N. SINGH and M. C. FLEMINGS, Trans. TMS-AIME, 1969, vol. 245, pp. 1803-09, 1811-19.

P. R. SPERRY is Senior Research Associate, Olin Corporation, New Haven, Conn.

Discussion submitted October 2, 1969. tion, with or without impurities, is completed by the formation of a quasibinary eutectic made up of aluminum solid solution and a phase which is crystallographically equivalent to $\mathrm{MgZn}_{2}$, as shown in the authors' Fig. 5(a). However, Strawbridge et al. ${ }^{20}$ have shown that zinc in this phase can be substituted for by aluminum plus copper, to the extreme of a ternary $\mathrm{Mg}(\mathrm{Al}, \mathrm{Cu})$ phase containing no $z$ inc at all. Therefore, a high concentration of zinc, copper, and magnesium can be expected to be present in eutectic regions of cast alloy 7075 . Upon reheating to sufficiently high temperperature, all three elements tend to dissolve but, simultaneously, $\mathrm{Al}_{2} \mathrm{CuMg}$ forms very rapidly from residual $\mathrm{MgZn}_{2}$ (containing $\mathrm{Al}+\mathrm{Cu}$ ) by a solid state reaction analogous to a peritectic or peritectoid transformation. This new phase, in turn, dissolves at a much lower rate. The composition range of alloy 7075 with respect to magnesium, zinc, and copper is such that some specific alloy compositions at some solutionizing temperatures can have a solid solution saturated with these three elements and the excess always appears as $\mathrm{Al}_{2} \mathrm{CuMg}$. Raising the solutionizing temperature will, of course, cause more rapid and complete dissolution. It is not uncommon to use temperatures as high as $500^{\circ} \mathrm{C}$ for solution treatment of light gage sheet where a lesser degree of heterogeneity exists than in less highly worked products. The equilibrium solidus temperature lies still higher than $500^{\circ} \mathrm{C}$, but local concentrations of $\mathrm{Al}_{2} \mathrm{CuMg}$ particles can result in nonequilibrium incipient melting at temperatures as low as $476^{\circ} \mathrm{C}$ unless the solutionizing temperature is approached very slowly.

There are occasions when small amounts of $\mathrm{CuAl}_{2}$ appear comingled with $\mathrm{MgZn}_{2}$ in the as-cast eutectic of alloy 7075, resulting from abnormally high proportions of copper to magnesium in the alloy. However, this $\mathrm{CuAl}_{2}$ also disappears rapidly upon subsequent heating, and it is clearly replaced by $\mathrm{Al}_{2} \mathrm{CuMg}$.

The most important point of this discussion concerns the reliability of making phase identifications by microprobe analysis without benefit of other crystallographic or metallographic evidence. It appears that some hazards exist and that more definitive work needs to be done to determine their causes.

20. D. J. Strawbridge, W. Hume-Rothery, and A. T. Little: J Inst. Metals, 1947-48, vol. 74, p. 191.

\section{Activity of Oxygen in Liquid Co-Ni Alloys}

\section{EDWIN S. TANKINS}

A knowledge of the thermodynamic behavior of dilute solutes in liquid metals and alloys is of importance in understanding and designing refining and alloy making processes. Since cobalt alloys are important technologically, it is of interest to study the effect of alloy-

EDWIN S. TANKINS is Metallurgist, Aero Materials Department, Naval Air Development Center, Warminster, Pa.

Manuscript submitted October 31, 1969. 